\title{
Plasma Infranatant
}

National Cancer Institute

\section{Source}

National Cancer Institute. Plasma Infranatant. NCI Thesaurus. Code C106554.

The liquid, solid or semi-solid lying below a liquid residue, which is separated by crystallization, precipitation or centrifugation of a plasma sample. 